\title{
Is addiction a myth? Donald Davidson's solution to the problem of akrasia says not*
}

\author{
Nick Heather ${ }^{1}$ and Gabriel Segal ${ }^{2}$ \\ ${ }^{1}$ Department of Psychology, Northumbria University, UK \\ ${ }^{2}$ Department of Philosophy, King's College London, UK
}

*This article is based on a presentation given at a Thematic Meeting of the Kettil Bruun Society, "Addiction: What is the added value of the concept today?” at Conference Hotel Majvik, Espoo, Helsinki, Finland, 14-17 October, 2012. Parts of this article are extracted with permission from: Heather, N. \& Segal, G. (2013). Understanding addiction: Donald Davidson and the problem of akrasia. Addiction Research \& Theory, 21, 445-452.

\begin{abstract}
An obvious problem for the concept of addiction is its portrayal as involving involuntary behavior in the face of the addict's intentional actions. This has led some writers to call addiction a myth and to describe the self-labeling of persons as addicts as an illustration of causal attribution. We argue that this position is seriously mistaken. We propose that it is possible to construct a meaningful concept of addiction without assuming it involves completely involuntary behavior and to do so within the language of agents engaging in intentional action. One way of doing so arises from the work of Donald Davidson (1917-2003), particularly his essay "How is weakness of the will possible?" (Davidson, 1969). Davidson proposes a solution to the classic philosophical problem (called the problem of akrasia or incontinence) of how it is logically possible for someone to perform an action against her better judgement, and his solution is relevant to an understanding of addiction (i.e., addiction is a class of akratic action). Thus, Davidson's solution to this philosophical problem is also an answer to the question of how it is possible to understand addiction without assuming it entails completely involuntary behavior. At the same time, Davidson's conclusion at the end of his essay - that the akrates cannot give a reason for preferring incontinent over continent action-suggests what addicts mean when they say they feel compelled to behave the way they do.
\end{abstract}

\section{Introduction: Addictive behavior is intentional}

Suppose someone who has been diagnosed as an alcoholic and is trying to remain abstinent finds herself in a high-risk situation, goes into a pub, buys a drink, and thus suffers a relapse. The high-risk situation in question may have been meeting some old drinking buddies who invited her to join them "just for a quick one"; it may have been an upsetting quarrel with her spouse; or it may have been the depressing thought that her life was empty and meaningless. Whatever the precipitating circumstances, we may well concede that the temptation to drink and the associated craving for a drink were, in some way and to some degree, beyond the person's control. But we surely cannot deny the palpable facts that she deliberately entered the door of the public house, asked for her preferred beverage, picked up a glass, put it to her lips, and drank the alcohol she had vowed to refrain from. All these are clearly intentional actions, involving a conscious desire to bring about some desired state of affairs and the execution of behavior aimed at achieving that end. Whatever temptations she may have been exposed to and whatever degree of craving she may have experienced, her drinking was not a reflex like a kneejerk, she did not take a drink absent-mindedly, she was not sleep-walking or hallucinating, she was not under the misapprehension that she was consuming some nonalcoholic beverage, and nobody was twisting her arm to force her to drink (all of which conditions might be reasons for thinking that the behavior was not intentional). On the other hand, if someone had put a gun to her head and threatened to shoot her if she drank, she would presumably have resisted her desire to do so. In what meaningful sense, then, can it be said that her behavior was involuntary or out of her control?

Put this way, the problem is simple and obvious. Yet it is astonishing how seldom such issues are ever addressed by addiction scientists, particularly by those interested in explaining addiction from the perspective of the medical, behavioral, or social sciences. (They are, of course, addressed by philosophers; see Mele, 1987; 2002; Pears, 
1984; Pickard, 2013; Segal, 2013; Wallace, 1999; Watson, 1999; among many others). It may be a fear of raising all the moral and legal complications that arise as soon as one appears to suggest that the addict's drinking might in some sense be within the realm of personal choice. Perhaps also there is a fear of appearing "unscientific" by raising the spectre of voluntarism in a causal explanation of behavior. Whatever the reason, we suggest that the problem we have raised-that of describing a meaningful concept of addiction in the face of what is obviously intentional behavior-is the central conceptual problem in the study of addiction and one that must be solved before real progress in understanding addiction can be made.

Some addiction specialists have clearly recognized this problem. In particular, John B. Davies, in his influential book The Myth of Addiction, has argued that what is called addiction is not a form of involuntary behavior but is freely chosen, like any normal behavior, and that the concept of addiction therefore represents a myth (Davies, 1997a). Similar views have been expressed by Schaler (2000) and are common among members of the public and among some lawyers (e.g., Wallace, 2013). To anticipate the later discussion in this article, we agree with Davies and with others that addiction is not completely involuntary behavior but do not agree that this makes addiction a myth. Thus, our main aim here is to explain how a meaningful and useful concept of addiction can be found while at the same time rejecting the idea that it is completely involuntary behavior over which the putative addict has no choice.

To meet this aim we develop here an argument based on a classic paper in the philosophy of action: an essay first published in 1969 by the late American philosopher, Donald Davidson (1917-2003), entitled "How is weakness of the will possible?” (Davidson, 1969, 1980a). A way of showing that addiction can be conceptualized without portraying it as being completely involuntary is to claim that it is a form of behavior known since the ancient Greeks as akrasia or, in more modern language, weakness of will. Davidson's essay was an attempt to show how weakness of will can be said to exist, and to demonstrate that it did not involve an inherent contradiction. This will be explained later but suffice it to state here our contention that, in explaining how weakness of will is logically possible, we can also explain how it is logically possible to have a concept of addiction, implying some restriction on choice, within the language of agents engaging in intentional action.

A subsidiary aim of this article is to use Davidson's essay to throw light on an aspect of the phenomenology of addiction: addicts' complaints that they feel compelled to behave the way they do. Without in any way subscribing to the view that addiction consists of, or can be usefully seen as, a form of compulsion, we nevertheless suggest a way, following Davidson, of understanding what addicts may mean when they say that they feel compelled to carry out addictive behavior. This will also serve to illustrate the benefits of seeing addiction as a kind of akrasia.

\section{The myth of addiction}

As noted above, Davies (1997a) argues that addiction is a myth and that the alleged addict's drug-related behavior is as much within the realm of personal choice as any other kind of voluntary behavior:

[P]eople take drugs because they want to and because it makes sense for them to do so given the choices available, rather than because they are compelled by the pharmacology of the drugs they take . . . most people who use drugs do so for their own reasons, on purpose, because they like it, and because they find no adequate reason for not doing so; rather than because they fall prey to some addictive illness which removes their capacity for voluntary behaviour. (p. x-xi)

At this point we must repeat that we agree entirely with Davies that so-called addicts are not incapable of voluntary behavior. However, we disagree that, with respect to their addictive behavior, they are free to make unconstrained choices or that the choices available to them are choices just like any other. Indeed, we believe that the task in trying to understand addiction is to describe precisely the nature of the constraints on choice with which the addict is confronted. For example, it is undoubtedly true that many people use drugs "because they find no adequate reason for not doing so"; if they are addicted, however, they do by definition have adequate reasons for not doing so but continue to use drugs despite those adequate reasons. We trust this will become clearer as we proceed.

The main evidence on which the claim for the involuntary nature of drug-taking is based, says Davies, is the selfreports, opinions, and statements of the so-called addicts themselves. However, when someone tells us he is addicted, this should not be understood as an objective description of a real state of affairs but as a causal attribution by a person attempting to make sense of the behavior to himself and, importantly, to others; the person attributes his harmful and undesirable behavior to some internal process called "addiction" which causes him to behave, apparently contrary to his will, in that way. The causal attribution is itself influenced by social factors, such as the status of the person with whom the addict is interacting when he accounts for his addictive behavior and the consequences of the attribution in terms of the practical advantages and disadvantages to him in making it.

An ingenious experiment by Davies and Baker (1987) can be used to illustrate this thesis. Twenty adult males who were regular heroin users (mean age of 20.1 years, range 17 to 26 years) were individually administered two parallel forms of a questionnaire separated by 10 to 14 days. The questionnaires were typical of those used in studies of drug-taking behavior and included items on drug consumption, attitudes toward drug-taking, self-reported criminality, and reasons for drug use. The first interview was carried out by a 26-year-old locally-known male heroin user who presented himself as having been recruited by a nearby university to help carry out interviews; the second was conducted by a 40-year-old "straight" (nondrug-using) interviewer who presented himself as a 
researcher from the university. At the end of the first interview, subjects were asked if they were willing to take part in a similar study in a week or so, and all those who successfully completed the first interview agreed to do so. Subjects received a different version of the questionnaire on each occasion and the two forms were presented as belonging to two separate studies with no connection with each other.

The results of this experiment showed, in general terms, that subjects consistently presented themselves as heavier drug users and as being more addicted when interviewed by the "straight" interviewer than when interviewed by the known heroin user. In the latter case, they gave the impression of having more choice and greater control over their drug use. The differences between the two sets of interview responses were substantial and clearly demonstrated that the people who used heroin presented themselves very differently depending on the person interviewing them. In discussing these findings, Davies (1997a) writes: "[P]eople are able to construct their explanations on the basis of their knowledge and experience of the attributions that others are likely to make about them; and when this occurs, attribution may be said to have a strategic component” (p. 122, italics original). Other experiments by Davies and his colleagues (White \& Davies, 1998; Heim, Davies, Cheyne, \& Smallwood, 2001; Davies, McConnochie, Ross, Heim, \& Wallace, 2004) support the view that what people say about drug use very much depends on whom they are talking to and in what context rather than reflecting any underlying objective state, neurophysiological, socio-psychological, or otherwise. These ideas were developed further by Davies (1997b) into a functional discourse model of drug use.

\section{Akrasia, weakness of will, and incontinence}

For present purposes the three terms in the heading of this section are synonymous. "Akrasia” is Aristotle's word for a problem identified by the ancient Greeks and commented on by philosophers down the ages ever since (Peijnenburg, 1996). Modern philosophers address the problem by referring to "incontinence" which is a rough translation of akrasia into English. At other times, modern philosophers refer to the problem simply as "weakness of will". Despite the common use of this phrase as an explanation rather than merely as a description of the phenomenon, and despite the tendency to assume weakness of will refers to a characterological trait, neither of which is intended here, this term is useful in pointing to the nature of the problem and will be used in places here.

The problem described by akrasia can be summarized by the words of St. Paul in his letter to the Romans: "I do not understand my own actions. For I do not do what I want, but the very thing I hate" (Romans 7:15 Revised Standard Version). In other words, akrasia occurs when someone acts intentionally counter to his own best judgement of what it is better to do; in these circumstances we often say that the person lacks the willpower to do what he knows or believes to be better to do. The term "akratic" refers to actions that show the property of akrasia and the person acting in this way is the "akrates."
The philosophical problem is to explain how this situation of judging it better not to do something and yet proceeding to do it is logically possible. It is important to note here that some have concluded that it is not logically possible. Most famously, according to Plato in the Protagoras, Socrates believed that "[n]o-one goes willingly toward the bad." Socrates thus rejected the notion of akrasia by insisting that what we do is always an expression of what we judge best to do and that weakness of will as defined above is therefore a logical absurdity (see Peijnenburg, 1996.)

The relevance of this body of philosophy to the study of addiction is simply that the philosophical issue of weakness of will subsumes what we have suggested is the central task in explaining addiction-that is, the problem of understanding how it is possible that someone continues to carry out an activity, like smoking, getting drunk, injecting heroin, or gambling, despite an awareness of the harm the activity is doing them, despite having decided that they do not want to do it, and despite repeated resolutions that they will refrain from doing it in future. In short, we assume that addiction is a form, albeit an extreme and repeated form, of weakness of will. In this connection, it is significant that, in the voluminous writings on akrasia in the philosophical literature, addictions of various kinds are often used to illustrate particular points being made. Thus, addiction is considered to be an interesting case for the study of weakness of will and consequently this study, in its turn, may contribute to an understanding of addiction. The crucial point for present purposes is that, if it is accepted that addiction is a form of akrasia, then it follows that addiction is not a myth.

\section{Donald Davidson on weakness of will}

In modern philosophical writings on weakness of will, Davidson's contributions have perhaps been most influential. In particular, the essay entitled "How is weakness of the will possible?" (Davidson, 1969, 1980a) has attracted a great deal of attention and comment among philosophers (e.g., Bratman, 1979; Charlton, 1988; Elster, 1999; Gjelsvik, 1999; Glüer, 2011; Kennett, 2001; Kotatko, Pagin, \& Segal, 2001). Davidson's essay will now be used to outline a possible solution to the particular problem mentioned at the beginning of this article: given the obviously intentional nature of what we call addictive behavior, what does it mean to say that someone is addicted?

Davidson first defines an incontinent action as follows:

In doing $x$, an agent acts incontinently if and only if:

a) the agent does $x$ intentionally;

b) the agent believes there is an alternative action $y$ open to him; and

c) the agent judges that, all things considered, it would be better to do $\mathrm{y}$ than to do $\mathrm{x}$.

To make this definition more real, it will be convenient to see $\mathrm{x}$ as the action of smoking a proffered cigarette after having resolved at some time in the past to quit smoking 
and to see y as turning down the offer and refraining from smoking. Note that, in Davidson's definition, it is necessary that the agent continues knowingly to judge that it would be better to do y (refrain from smoking) at the time he does $\mathrm{x}$ (smokes). This is known to philosophers as "clear-eyed akrasia" (Setiya, 2007), and it is arguably precisely the situation the addict finds herself in. It is this interpretation of akrasia that is the focus of this article.

The problem Davidson sets out to solve in his essay is that of reconciling three principles that are apparently inconsistent with each other:

P1 If an agent wants to do $\mathrm{x}$ more than he wants to do $\mathrm{y}$ and he believes himself free to do either $\mathrm{x}$ or $\mathrm{y}$, then he will intentionally do $\mathrm{x}$ if he does either $\mathrm{x}$ or $\mathrm{y}$ intentionally.

P2 If an agent judges that it would be better to do $\mathrm{x}$ than to do $\mathrm{y}$, then he wants to do $\mathrm{x}$ more than he wants to do $\mathrm{y}$.

P3 There are incontinent actions.

Following Mele (1987, p. 33), we can collapse the first two principles above in a way that, via "wanting to do $\mathrm{x}$ more than y" in both P1 and P2, connects judgment and action:

$\mathrm{P}^{*} \quad$ If an agent judges that it would be better to do $\mathrm{x}$ than $\mathrm{y}$, and he believes himself free to do either $\mathrm{x}$ or $\mathrm{y}$, then he will intentionally do $\mathrm{x}$ if he does either $\mathrm{x}$ or $\mathrm{y}$ intentionally.

Now, P* may be directly compared with Davidson's definition of incontinence above: the former says that, if the agent judges it would be better to do $\mathrm{x}$ than to do $\mathrm{y}$, he will do $\mathrm{x}$; the latter says that, in incontinence, if the agent judges it would be better to do $\mathrm{y}$ than to do $\mathrm{x}$, he will do $\mathrm{x}$. Here is the contradiction Davidson sets out to resolve. How can the statements in P1 and P2, and collapsed in P*, be true if it is also true that there are incontinent actions, which have just been defined as doing something when one judges it better to do something else? $\mathrm{P}^{*}$ and $\mathrm{P} 3$ appear to contradict one another. Put another way, how is it possible to say that incontinent actions exist given the intuitive understanding of intentional actions as always selecting what seems to the agent to be the best option? This is clearly a general description of the problem described earlier: how can we make sense of the idea that an alcoholic intentionally takes a drink when she judges it better, on balance, that she should not take it? Thus, Davidson's solution to this general problem will also be a solution to the more particular problem with which we are confronted in the study of addiction.

Davidson's solution to the problem of incontinence rests on the idea that there are two different kinds of judgement involved in the apparently contradictory statements above. This solution concerns the nature of practical reasoning (i.e., reasoning about action) and turns on the distinction between two sorts of practical judgement: judging a course of action to be prima facie correct (or prima facie better than an alternative) and judging it to be correct absolutely or sans phrase (i.e., without exception, unconditionally, or "all-out"). Since the agent in the above definition of incontinence judges that it would be better, all things considered (i.e., relative to all facts, beliefs, and values he thinks relevant to the decision), to do y (not smoke) than to do $\mathrm{x}$ (smoke), it is a prima facie judgement - that is, a conditional evaluative judgement based on the truth of all the facts, beliefs, etc. that have been taken into consideration, but that could conceivably be wrong. This kind of judgement, Davidson says, does not lead immediately to action. By contrast, the judgement in $\mathrm{P} *$ above is an unconditional judgement that doing $\mathrm{x}$ is best thing to do without exception and it is such judgements that do lead immediately to action. It is the failure to understand the distinction between these two sorts of practical judgement, and the failure to appreciate that the judgement involved in incontinence is only a conditional kind of judgement, that has led thinkers to conclude that akratic action is impossible. Thus, the occurrence of incontinent actions does not falsify $\mathrm{P}^{*}$ above, because the judgement with which $\mathrm{P}^{*}$ is concerned is an unconditional judgement.

Bearing in mind that we are concerned here with the nature of practical reasoning, the definition of incontinence given earlier can be modified to say that an action, $\mathrm{x}$, is incontinent provided the agent has a better reason for doing something else or, in this case, for not doing $\mathrm{x}$. Thus, the agent does $\mathrm{x}$ for a reason, $\mathrm{r}$, but he also has a better reason, $r^{\prime}$ (a reason that includes $r$ and more), for doing $y$. The conclusion is that there is no inconsistency between claiming that the agent thinks it better, relative to all apparently relevant facts, to do $\mathrm{y}$ (or not to do $\mathrm{x}$ ) and claiming that the agent thinks it better absolutely to do $\mathrm{x}$ than to do y; there is no logical conflict between the two propositions.

To further clarify the difference between a prima facie judgement and an unconditional judgement in his thinking, another essay by Davidson (1980b) may be helpful. Here he maintains that a certain kind of unconditional or "allout” judgment, "a judgment that something I think I can do ... is desirable " (p. 101) is an intention. In the paper "How is weakness of the will possible?" $(1969,1980 a)$ that is the focus of the present article, Davidson writes: "Intentional action . . . is geared directly to unconditional judgments like 'It would be better to do a than to do $\underline{b}$. ' Reasoning that stops at conditional judgments . . . is practical in its subject, not in its issue” (p. 39). Thus, what this prima facie reasoning stops short of is the formation of an intention. And what happens in cases of incontinent action, according to Davidson, is that the agent does not form an intention to do what he judges to be best, all things considered. His weakness (akrasia) is exhibited, not in a failure to act on an unconditional judgment (i.e., on an intention), but rather in his failure to form an intention (and, hence, act) in accordance with an "all things considered" judgment, a judgment that is conditional in form (see Mele, 1987, p. 34).

Mele (1987, p. 163) reinforces this point by quoting from Davidson (1985): 
I am committed to the view that an agent is incontinent only if he fails to reason from a conditional "all things considered" judgment that a certain course of action is best to the unconditional conclusion that that course of action is best. .. [S] [uch a failure is just what I defined to be a case of incontinence, and what I argued was possible. . . So to fail to reason to the right "conclusion" means, in practical reasoning, to fail to form attitudes in a rational, coherent way. Among those attitudes are intentions. Failure to form an intention in accord with the principle of continence ${ }^{1}$ is, I still think, all too possible. (p. 246)

Consider our smoker. When offered the cigarette, he says, "I know I shouldn't but I will." He has a reason, r, for accepting the proffered cigarette: it will give him immediate pleasure. But he knows that this pleasure is not the only relevant consideration; he also wants to live a long and healthy life and not encourage his children to take up smoking. Taking all known relevant factors into account, he has a reason, r', to refuse the cigarette. If he had refused, then he would have acted on r', and his action would have been continent: it would have been the best thing for him to do, given all he knows. If he smokes the cigarette, then he is acting on $r$, a subset of r', and his action is incontinent. Reason $r$ gives him a reason to smoke but this reason is insufficient, given r': r' includes $r$ itself and more, and overall provides a better reason for acting than does $r$. But since $r$ ' is itself not the totality of truths, he is not strictly speaking illogical. For all he knows, it might be right to smoke after all. $\mathrm{He}$ is, however, irrational: he acts on $\mathrm{r}$ rather than that $\mathrm{r}$ ' and he has no reason for doing that.

It is important to bear in mind here that Davidson's treatment of the problem of akrasia is a philosophical one; he does not attempt to provide an explanation, neurobiological, psychological, socio-psychological, or otherwise, of weakness of will and makes no attempt to specify the conditions under which the incontinent rather than the continent act will be chosen; he is concerned only to solve a problem of logic. In particular, Davidson does not try to explain why, in the case of incontinence, there is a disconnection between the agent's all-things-considered judgement that $\mathrm{y}$ would be best and her unconditional intention to do x. Interestingly, Davidson (1982) does offer an explanation of akrasia, but it would take us too far afield to consider it in this article, which is concerned only to show that addiction is not a myth. Suffice it to say that relationships between the philosophical concept of akrasia and empirical research on addiction in the fields of neuroscience, behavioral economics, and cognitive/ behavioral psychology will be explored elsewhere (Heather \& Segal, in press).

\footnotetext{
${ }^{1}$ The principle of continence says: "Perform the action judged best on the basis of all available relevant reasons" (Davidson, 1980a, p. 41).
}

\section{Implications for an understanding of the experience of compulsion in addiction}

So what, in short, is the fault in incontinence? It is not, Davidson says, that the incontinent agent holds logically contradictory beliefs: "What is wrong, however, is that the incontinent person acts and judges irrationally, for that is surely what we must say of someone who goes against his or her own best judgement" (Davidson, 1980a, p. 41). The irrationality stems from the fact that the agent's reason for doing $\mathrm{x}$ is, as it were, insulated as a practical action from the better reason for not doing $\mathrm{x}$.

In a key passage, Davidson summarizes his position as follows:

Why would anyone ever perform an action when he thought that, everything considered, another action would be better? If this is a request for a psychological explanation, the answers will no doubt refer to the interesting phenomena familiar from most discussions of incontinence: self-deception, overpowering desires, lack of imagination, and the rest. But if the question is read, what is the agent's reason for doing $(\mathrm{x})$ when he believes it would be better, all things considered, to do another thing, then the answer must be: for this, the agent has no reason. (p. 42)

In a footnote, Davidson adds: "Of course he has a reason for doing (x); what he lacks is a reason for not letting his better reason for not doing (x) prevail" (p. 42). He concludes: "What is special in incontinence is that the actor cannot understand himself: he recognizes, in his own intentional behaviour, something essentially surd” (p. 42).

It is important to remind ourselves that Davidson is not attempting here to provide a psychological explanation of weakness of will, nor more generally to describe those conditions under which it will occur and those under which it will not. Rather, he is concerned to show that intentional weakness of will is not a logical impossibility and, in doing so, demonstrates that the incontinent agent cannot be expected to provide a proper reason for his irrational behavior. We believe that this insight has a striking relevance to the phenomenology of addiction.

Surd means "inexpressible" and here is the essence of the addict's predicament. When asked, or when she asks herself, why she broke her resolution to refrain from smoking, getting drunk, or whatever it is that she vowed to refrain from, she cannot tell us (or herself); she cannot provide a satisfactory account of her behavior. To paraphrase both St. Paul and Davidson, the addict does not understand her own behavior, and it is in this sense that it is out of her control. This, we suggest, is at least a part of what she means when she tells us she is addicted: she keeps doing something without knowing why it is that she keeps on and cannot refrain from doing it. This may also be the reason why addicts willingly seek help or formal treatment for their problem; since they cannot understand their own behavior, they hope that a helper or therapist can understand it and advise how to change it. 
This may also represent a sense in which the addict reports feeling compelled to engage in addictive behavior-the subjective sense of not being able to understand one's past behavior and therefore feeling that one must have been driven by some extrapersonal force to carry it out. If one cannot understand why one has repeatedly done something one would rather not have done and, on the basis of past evidence, is likely to continue doing, then one is likely to feel that one was and is compelled to keep doing it.

This may also be why the addict in Davies and Baker's (1987) experiment described above adopts whatever account of addictive behavior seems most appropriate at the time and in the situation he delivers it. As we have seen, the only truly accurate response the addict possesses to questions about why he continues to use in the face of his recognition that it is harmful for him to do so is that he does not have a reason for this behavior. But, assuming he feels that it is necessary to offer some kind of explanation, he appeals to "choice" when talking to the fellow addict and "addiction" when talking to the university researcher. These responses may have been made to obtain the functional advantages Davies (1997a) describes but, from the viewpoint expressed here, this does not make addiction a myth.

\section{Acknowledgements}

The authors are grateful to two anonymous reviewers for helpful comments on an earlier draft of this paper. We are also grateful to Varpu Rantala for challenging us to clarify our understanding of Davidson's position on akrasia.

\section{References}

Bratman, M. (1979). Practical reasoning and weakness of the will. Nous, 13, 153-171.

Charlton, W. (1988). Weakness of will. Edinburgh, Scotland: Blackwell.

Davidson, D. (1969). How is weakness of the will possible? In J. Feinberg (Ed.), Moral concepts (pp. 93-113). Oxford, England: Oxford University Press.

Davidson, D. (1980a). How is weakness of the will possible? In D. Davidson (Ed.), Essays on actions and events (pp. 21-42). Oxford, England: Oxford University Press.

Davidson, D. (1980b). Intending. In D. Davidson (Ed.), Essays on actions and events (pp. 83-102). Oxford, England: Oxford University Press.

Davidson, D. (1982). Paradoxes of irrationality. In R. Wollheim \& J. Hopkins (Eds.), Philosophical essays on Freud (pp. 289-305). Cambridge, England: Cambridge University Press.

Davidson, D. (1985). Replies to Essays I-IX. In B. Vermazen \& M. B. Hintikka (Eds.), Essays on Davidson: Actions and events (pp. 242-252). Oxford, England: Oxford University Press.

Davies, J., McConnochie, F., Ross, A., Heim, D., \& Wallace, B. (2004). Evidence for social learning in the self-presentation of alcohol problems. Alcohol \& Alcoholism, 39, 346-350.

Davies, J. B. (1997a). The myth of addiction ( $2^{\text {nd }}$ ed.). Reading, England: Harwood Academic Publishers.

Davies, J. B. (1997b). Drugspeak: The analysis of drug discourse. Amsterdam, The Netherlands: Harwood Academic Publishers.

Davies, J. B., \& Baker, R. (1987). The impact of selfpresentation and interviewer bias effects on selfreported heroin use. British Journal of Addiction, 82, 907-912.

Elster, J. (1999). Davidson on weakness of will and selfdeception. In L. E. Hahn (Ed.), The philosophy of Donald Davidson (Library of Living Philosophers Vol. XXVII, pp. 425-441). Chicago, IL, United States: Open Court Publishing Company.

Gjelsvik, O. (1999). Addiction, weakness of the will, and relapse. In J. Elster \& O. -J. Skog (Eds.), Getting hooked: rationality and addiction (pp. 47-64). Cambridge, England: Cambridge University Press.

Glüer, K. (2011). Donald Davidson: A short introduction. Oxford, England: Oxford University Press.

Heather, N., \& Segal, G. (in press). Addiction and choice: rethinking the relationship. Oxford, England: Oxford University Press.

Heim, D., Davies, J. B., Cheyne, B., \& Smallwood, J. (2001). Addiction as functional representation. Journal of Community \& Applied Social Psychology, $11,57-62$.

Kennett, J. (2001). Agency and responsibility: A commonsense moral psychology. Oxford, England: Oxford University Press.

Kotatko, P., Pagin P., \& Segal, G. (2002). Interpreting Davidson. Stanford, CA, United States: CSKI Publications.

Mele, A. R. (1987). Irrationality: An essay on akrasia, selfdeception, and self-control. Oxford, England: Oxford University Press.

Mele, A. R. (2002). Akratics and addicts. American Philosophical Quarterly, 39, 153-167.

Pears, D. (1984). Motivated irrationality. Oxford, England: Oxford University Press.

Peijnenburg, J. (1996). Acting against one's best judgement: An enquiry into practical reasoning, dispositions and weakness of will. (Doctoral thesis, Rijksuniversiteit Groningen, the Netherlands).

Pickard, H. (2013). Responsibility without blame: Philosophical reflections on clinical practice. In K. W. M. Fulford, M. Davies, R. Gipps, G. Graham, J. Sadler, G. Stanghellini, \& T. Thornton (Eds.), Oxford handbook of philosophy of psychiatry (pp. 11341154). Oxford, England: Oxford University Press.

Schaler, J. A. (2000). Addiction is a choice. Chicago, IL, United States: Open Court Publishing.

Segal, G. M. A. (2013). Alcoholism, disease and insanity. Philosophy, Psychiatry and Psychology, 20, 207-315.

Setiya, K. (2007). Reasons without rationalism. Princeton, NJ, United States: Princeton University Press.

Wallace, D. (2013). Addiction postulates and legal causation, or who's in charge, person or brain? Journal of the American Academy of Psychiatry and the Law, 41, 92-97. 
Wallace, J. R. (1999). Addiction as defect of the will: some philosophical reflections. Law \& Philosophy, 18, 621654.

Watson, G. (1999). Disordered appetites: Addiction, compulsion and dependence. In J. Elster (Ed.), Addiction: Entries and exits (pp. 3-28). New York, NY, United States: Russell Sage Foundation.

White, M., \& Davies, J. (1998). The effects of context and sensitivity on self-reported attitudes towards drugs. Journal of Substance Misuse, 3, 213-220. 